\title{
COMPLEXES BASED ON COLLAGEN AND KERATIN FOR APPLICATIONS
} IN AGRICULTURE

\author{
MIHAELA-DOINA NICULESCU ${ }^{1}$, CRISTINA EMANUELA ENASCUTA $^{2,3}$, \\ MARIA STANCA ${ }^{1,4}$, CARMEN CORNELIA GAIDAU $^{1}$, COSMIN ALEXE $^{1}$, \\ MIHAI GIDEA ${ }^{5}$, MARIUS BECHERITU ${ }^{6}$ \\ ${ }^{1}$ INCDTP-Leather and Footwear Research Institute Division, 93 Ion Minulescu Street, Bucharest, \\ Romania, mihaelaniculescu59@yahoo.com \\ ${ }^{2}$ National Institute for Research \& Development in Chemistry and Petrochemistry ICECHIM, \\ Bucharest, Romania, cristina.enascuta@gmail.com \\ ${ }^{3}$ Doctoral School of Faculty of Applied Chemistry and Materials Science, Department of \\ Chemical and Biochemical Engineering, University Politehnica of Bucharest, Romania \\ ${ }^{4}$ Doctoral School of Faculty of Applied Chemistry and Materials Science, Department of Science \\ and Engineering of Oxide Materials and Nanomaterials, University Politehnica of Bucharest, \\ Romania \\ ${ }^{5}$ University of Agronomic Science and Veterinary Medicine, 59, Marasti St, sector 1, Bucharest, \\ Romania,gideam@yahoo.com \\ ${ }^{6}$ SC Probstdorfer Saatzucht Romania SRL, 20 Siriului St, sector 1, Bucharest, Romania, \\ marius.becheritu@probstdorfer.ro
}

\begin{abstract}
In the circular economy context, the use of proteins from collagen and keratin by-products of leather industry to obtain products for agriculture serves to reduce the carbon footprint generated from industry by reducing the amount of chemical synthesis products administered in agricultural technologies. This paper presents complexes based on collagen and keratin extracts obtained from by-products of the leather industry and their characterization. Thermal and chemical-enzymatic hydrolysis of semi-processed leather and degreased wool by-products was performed for protein extraction. Complexes were obtained by addition and crosslinking with active principles and vegetable tannins to collagen and keratin extracts. The characterization of complexes was performed based on the results of analytical investigations by physico-chemical methods: volumetry, potentiometry, IR spectroscopy, Dynamic Light Scattering and Texture Analysis. It has been found that collagen and keratin extracts contain sufficient proportions of small and medium size components size, of the order of 1-100 nm and of 100-1000 nm, specific for free amino acids and small oligopeptides with a role in bio stimulating seed germination, but also contain large size components, over $1000 \mathrm{~nm}$, in considerable proportions, which provide the adhesive and filmforming properties, with a role in foliar application and retarded release of amino acids.
\end{abstract}

Keywords: by-products, proteinic complexes, texture analysis.

\section{INTRODUCTION}

The use of protein extracts as a source of nitrogen for biostimulation, plant nutrition and protection, is a constant concern in research and in recent years there have been important results in this direction.

Unlike inorganic nitrogen-based fertilizers that are used predominantly in intensive agriculture, the main advantages of protein extracts administered in crops are their ecological relationship with plants and soil, but especially the systemic effects of biostimulation and protection under stress. A major advantage is the availability of proteins as secondary resources in aquaculture, food industry, leather industry (Li et al., 2020; Hukmi et al., 2018; Lavinska et al., 2017).

Protein extracts are a valuable source of nitrogen (nutrients) for agriculture, which can be used by both root and foliar application. The root application favors the release of the organic fraction in the soil, preventing dehydration due to the high rate of absorption 
through the roots, and by foliar application the nutritional role is amplified by the role of vehicle for microelements. Protein compounds offer long-lasting fertilizing effects compared to inorganic fertilizers, and by functionalizing with various plant extracts, protective effects on crops can be induced against pests (fungi and insects).

The intelligent use of secondary protein resources for plant nutrition, increasing soil fertility and reducing the carbon footprint, is an ecological alternative to synthetic materials and promoting sustainable agriculture in the context of the circular economy.

This paper presents complexes based on collagen and keratin extracts obtained from by-products of the leather industry and their characterization. The collagen and keratin extracts from the leather processing by-products were used to obtain complexes products with specific properties for the agricultural field, with effects on germination, nutrition and plant protection in various stages of vegetation. Also, the protein complexes properties can be exploited in other applications (Matyasovsky et al., 2017; Ranjithkumar et al., 2019), in accordance with the current trends of circular economy development.

\section{EXPERIMENTAL PART}

\section{Materials}

The bovine leather by-products and wool by-products from the Leather and Footwear Research Institute Division, Romania, for collagen and keratin extraction, as gelatin with average molecular weight over $30 \mathrm{kDa}$ and collagen and keratin hydrolysate with average molecular weight below $15 \mathrm{kDa}$.

Formic acid $80 \%$ from SC CHIMOPAR TRADING SRL, for pH corrections.

Ammonia solution $25 \%$ p.a, anhydrous sodium carbonate p.a from Chimreactiv SRL and ethoxylated alkyl non-ionic detergent from Borron SE for wool degreasing.

Hydrated calcium oxide p.a from SC Cristal R Chim SRL for leather and wool by-products hydrolysis.

Vegetable tara tannin from Leather Quimica SLU was used as powder with volatile matter content 8.6 and tannin content $39 \%$ to obtain tannin extract.

Glycerol were products of SC Chimopar SA Romania.

\section{Procedures}

Bovine gelatin was obtained by thermal hydrolysis of semi-processed leather byproducts at $70^{\circ} \mathrm{C}$ temperature and $\mathrm{pH} 4.0$.

The collagen hydrolysate was obtained by chemical-enzymatic hydrolysis at $60^{\circ} \mathrm{C}$ temperature and $\mathrm{pH}$ 8.0-8.5.

The keratin hydrolysate was obtained by chemical hydrolysis at $80^{\circ} \mathrm{C}$ temperature for 24-28 hours.

The Tara tannin extract (with 5\% dry substance, $4 \%$ tanning substances) was obtained by hydrolyzing the Tara powder in water at a temperature of $60-80^{\circ} \mathrm{C}$ for a period of $1-2$ hours, centrifugation and vacuum filtration on cellulosic membranes (Gaidau et al., 2014).

The complexes based on collagen or collagen and keratin were made by continuously stirring the gelatin with collagen or keratin hydrolysate additivatedcrosslinked with glycerol and tannin extract at $50-60^{\circ} \mathrm{C}$ for $40-90$ minutes.

\section{Analytical Methods}

The collagen and keratin extracts and their complexes were analysed by gravimetric methods, dry substance (SR EN ISO 4684:2006) and total ash (SR EN ISO 4047:2002), 
by volumetric methods, in terms of total nitrogen and protein substance (SR ISO 5397:1996), aminic nitrogen (ICPI protocol) by potentiometric method for $\mathrm{pH}$ measurement (SR EN ISO 4045:2008).

Dynamic Light Scattering was used for size particle determination and distribution by ZetaSizer device Nano ZS (Malvern, UK).

Texture tests of complexes based on collagen and keratin were carried out using a TEX'AN texture analyser.

IR spectroscopy was used for structural analysis by FT/IR-4200 (Jasco) with ATR device equipped.

\section{RESULTS AND DISCUSSIONS}

To obtain collagen and keratin complexes, the following protein extracts were prepared: GA gelatin, WH collagen hydrolysate, KH keratin hydrolysate, with the chemical characteristics presented in Table 1.

Table 1. Characteristics of protein extracts

\begin{tabular}{lcccc}
\hline \multicolumn{1}{c}{ Characteristics } & MU & Gelatin GB & \multicolumn{2}{c}{ Hydrolysates } \\
& & & WH & KH \\
\hline Dry substance & $\%$ & 14.52 & - & - \\
Volatile matter & $\%$ & - & 10.11 & 8.50 \\
Total ash & $\%$ & 0.20 & 12.58 & 12.28 \\
Total nitrogen & $\%$ & 16.41 & 12.08 & 12.55 \\
Protein substance & $\%$ & 92.67 & 67.89 & 76.04 \\
Amino nitrogen & $\%$ & 0.50 & 1.16 & 0.70 \\
pH analytical solution & - & 4.42 & 8.90 & 7.75 \\
\hline
\end{tabular}

The analysis of collagen and keratin hydrolysates by Dynamic Light Scattering (DLS) presented in Figure 1, (i) for WH collagen hydrolysate and (ii) for KH keratin hydrolysate, highlights the existence of small peptide fragments, in the specific "nano" field in this case for free amino acids and oligopeptides.

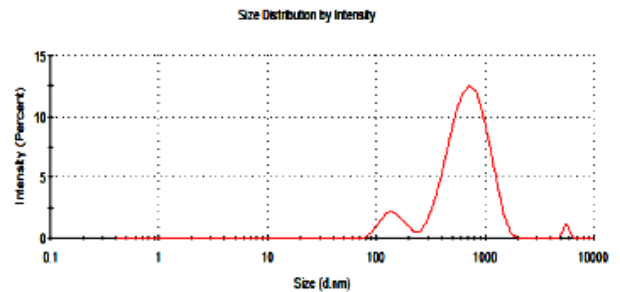

(i)

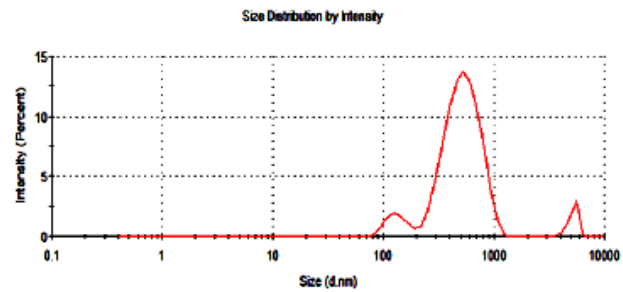

(ii)

Figure 1. Particle size in protein hydrolysates

The particle size distribution in collagen and keratin hydrolysates is shown in Table 2:

Table 2. Particle size distribution in protein hydrolysates

\begin{tabular}{lccc}
\hline \multicolumn{1}{c}{ Sample } & \multicolumn{2}{c}{ Particle size share } \\
& $10-100 \mathrm{~nm}$ & $100-1000 \mathrm{~nm}$ & $1000-10000 \mathrm{~nm}$ \\
\hline Collagen hydrolysate, WH & 0.5 & 83.6 & 15.9 \\
Keratin hydrolysate, KH & 0.7 & 93.5 & 5.8 \\
\hline
\end{tabular}

https://doi.org/10.24264/icams-2020.II.19 
DLS analysis reveals the existence of a higher percentage of particles below 1000 $\mathrm{nm}$ in collagen hydrolysate, being consistent with the higher content of amino nitrogen, which indicates a lower average molecular weight of collagen hydrolysate compared to keratin hydrolysate.

Gelatin and hydrolysates combined to form two types of complex gels, one based on collagen, GW and one based on collagen-keratin, GK, plasticized with glycerol and crosslinked with vegetable tannin extract. The chemical characteristics of the gels are presented in Table 3.

Table 3. Characteristics of protein gels

\begin{tabular}{lccc}
\hline \multicolumn{1}{c}{ Characteristics } & MU & GW & GK \\
\hline Dry substance & $\%$ & 32.48 & 29.39 \\
Total ash & $\%$ & 2.71 & 4.05 \\
Total nitrogen & $\%$ & 9.76 & 10.04 \\
Protein substance & $\%$ & 54.85 & 56.42 \\
Amino nitrogen & $\%$ & 0.67 & 0.48 \\
pH analytical solution & - & 5.76 & 5.39 \\
\hline
\end{tabular}

The gels strength of proteinic complexes formed by cross-linking and additivation was studied in comparison with gelatin in standard conditions by Direct Compression (CD) test. The results of the analysis are shown in Figure 2, for gelatin (a), collagen complex (b) and collagen-keratin complex (c).

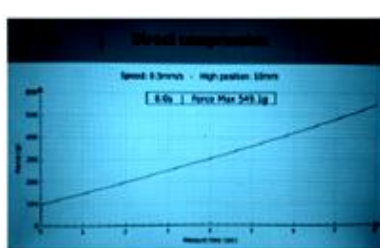

(a) $\mathrm{GB}$

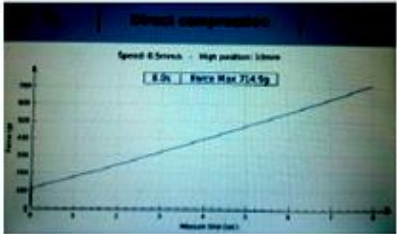

(b) GW

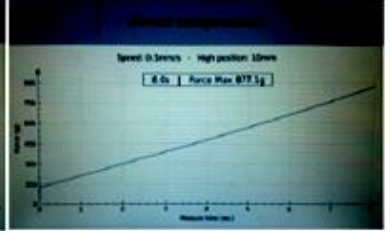

(c) GK

Figure 2. The comparative gels strength

It is found that the addition of gelatin with hydrolysates, and crosslinking lead to gels with a significantly higher strength, the largest increase being recorded by the gel additivated with keratin. The increase of the gelatin strength by additivation and crosslinking is the consequence of bond formation and new compounds that consolidate the newly formed structures.

The complete textural analysis of collagen and keratin based complexes for agricultural applications, whether they are plant or soil fertilizers, support bands for very small seeds, biodegradable packaging, etc. is done by Compression-RelaxationTraction (CRT) tests. By CRT test three consecutive phases are carried out: compression followed by a relaxation phase without movement where the reaction force (elastic thrust) of the sample is measured, then the probe is lifted while the fluid's traction force is measured, indicating its adhesiveness.

CRT tests measure the consistency, elasticity and adhesiveness and enable relevant parameters to be selected to define a product's texture, which will be related to its hardness, cohesion, and adhesiveness or free-running nature. 
Figure 3 shows the complete textural analysis of gelatin and collagen and keratin based complexes.

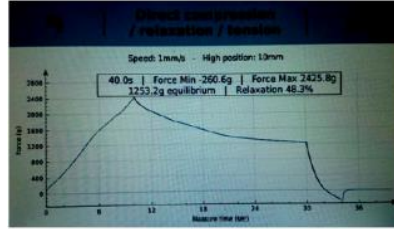

(A) GB

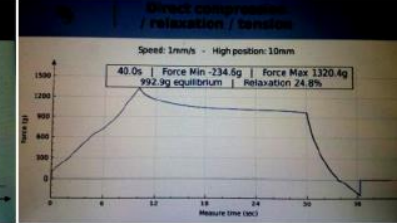

(B) GW

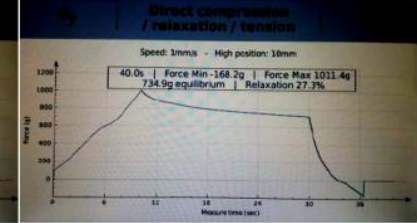

(C) GK

Figure 3. The Compression-Relaxation-Traction tests

The three phases can be identified on the curve Force =f(time): Fmax, which is the product's consistency in terms of defined compression (probe and distance); \% Relaxation, which is inversely proportional to the product's elasticity; Fmin, which reflects the traction or adhesion force of the product on the probe when it is brought out of the sample. The results of CRT tests show that the addition-crosslinking of gelatin causes a decrease in consistency but a pronounced increase in the elasticity of the gels, compared to the control gelatin, as well as a lower adhesiveness to the probe, without noticing significant differences between the two gels, only differences from gelatin.

According to response curve and the quantified values of these parameters, different textures of products can be compared and ranked.

The physical properties of the protein complexes are the consequence of the structural changes occurred following the crosslinking of the protein extracts with Tara tanning agent, highlighted by the IR spectral analysis. IR spectra show the spectral analysis of PW (in I) and PK (in II) films, formed by GW and GK gels, respectively, compared to gelatin (GB) and collagen hydrolysates (WH in I) and keratin (KH in II), respectively. IR spectra are presented in Figure 4.
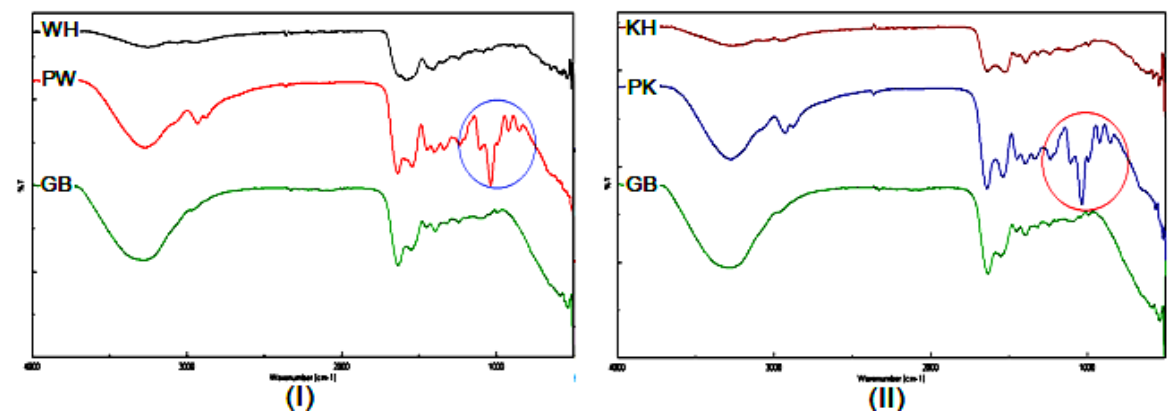

Figure 4. IR spectral analysis of proteinic complexes

The comparative analysis reveals that, in the spectra of the films formed by crosslinking the combinations of collagen extracts and combinations of collagen and keratin extracts with Tara tanning agent, there are missing peaks compared to hydrolysates, from the characteristic band $2600-3100 \mathrm{~cm}^{-1}$ specific to free amino acids and from band $1230-1260 \mathrm{~cm}^{-1}$ also specific to amino acids, while new peaks appear, non-existent in gelatin and hydrolysates, in the characteristic band $724-1174 \mathrm{~cm}^{-1}$. The common peaks in the films have frequencies and intensities slightly modified compared 
to those existing in gelatin and hydrolysates. Changes in crosslinking conditions can be attributed to the recombination of proteins of different sizes and the formation of larger peptide chains, specific to film-forming materials.

Testing complexes based on collagen and keratin to cover rapeseed as an outer layer of coating and monitoring of rapeseed crops in which seeds coated in this manner were used, led to superior results compared to control crops, established with conventionally treated seeds. There was a significant increase in germination compared to the control, as well as a better subsequent development of the plants. The overall development of the plants, both of the aerial part and of the underground part, was constant and much better highlighted than that of the untreated control.

\section{CONCLUSIONS}

The addition of collagen or keratin hydrolysates into gelatin provides a content of free amino acids and small oligopeptides with a role in bio stimulating seed germination. Crosslinking of collagen and keratin extracts with Tara tanning agent improves the film-forming properties and elasticity of the protein complexes. Collagen and keratin extracts are an alternative to the replacement of synthetic amino acids used to stimulate germination and plant development.

\section{Acknowledgements}

This work was supported by a grant of the Romanian National Authority for Scientific Research and Innovation CCCDI - UEFISCDI, project no. PN-III-P3-3.5EUK-2016-0029/COLL-RAPE, a grant of Core Program, project no. PN 19.17.01.02, and by the Operational Programme Human Capital of the Ministry of European Funds through the Financial Agreement 51668/09.07.2019, SMIS code 124705; and the article is funded by the Ministry of Research and Innovation within Program 1 - Development of the national RD system, Subprogram 1.2 - Institutional Performance - RDI excellence funding projects, Contract no. 6 PFE/16.10.2018.

\section{REFERENCES}

Gaidau, C., Simion, D., Niculescu, M.D., Paun, G., Popescu, M., Bacardit, A., Casas, C. (2014), “Tara Tannin Extract Improvement. Part I: Extraction and Concentration Through Membranary Filtration Techniques” Rev. Chim.-Bucharest, 65(8), 929-933

Hukmi, N. M. M. and Sarbon, N. M. (2018), "Isolation and characterization of acid soluble collagen (ASC) and pepsin soluble collagen (PSC) extracted from silver catfish (Pangasius sp.) skin”, International Food Research Journal, 25(6), 2601-2607.

Lawinska, K., Gendaszewska, D., Grzesiak, E., Jagiello, J. and Obraniak, A. (2017), "Coating of leguminosarum seeds with collagen hydrolyzates from tanning waste", Przemysl Chemiczny, 96(11), 1877-1880, 10.15199/62.2017.11.24.

Li, P.H., Lu, W.C., Chan, Y.J., Ko, W.C., Jung, C.C., Duynh, T.H., Ji, Y.X. (2020), "Extraction and characterization of collagen from sea cucumber (holothuria cinerascens) and its potential application in moisturizing cosmetics", Aquaculture, 515, 734590, 10.1016/J.Aquaculture.2019.734590.

Matyasovsky, J., Jurkovic, P., Skultety, J., et al. (2017), "Collagen and keratin as environmentally friendly natural polymers for modification of wood adhesives", in: Gatecka A., Wood-Science-Economy 2nd International Scientific Conference Proceedings, Wood Technology Institute, Poznan, Poland, 73.

Ranjithkumar, A., Sundar, V.J., Rose, C., Muralidharan, C. (2019), “Amino Acid Enriched Proteinous Wastes: Recovery and Reuse in Leather Making" Waste and Biomass Valorization, online, 10.1007/s12649-019-00912-6.

https://doi.org/10.24264/icams-2020.II.19 